INTERSTITIAL LUNG DISEASE

\title{
Involvement of dendritic cells in sarcoidosis
}

\author{
M Ota, R Amakawa, K Uehira, T lto, Y Yagi, A Oshiro, Y Date, H Oyaizu, T Shigeki, Y Ozaki, \\ K Yamaguchi, Y Uemura, S Yonezu, S Fukuhara
}

Thorax 2004;59:408-413. doi: 10.1136/thx.2003.006049

\begin{abstract}
See end of article for authors' affiliations

Correspondence to: Dr R Amakawa, First Department of Internal Medicine, Kansai Medical University, 10-15

Fumizono-cho, Moriguchi

City, Osaka 570-8506, Japan; amakawa@takii. kmu.ac.jp
\end{abstract}

Received 27February 2003 Accepted 10 October 2003
Background: Sarcoidosis is a systemic granulomatous disease of unknown aetiology. It has been suggested that Thelper type 1 (Th 1) polarisation is associated with the pathophysiology of sarcoidosis, but the mechanism of skewing towards Th1 has not been elucidated. Dendritic cells (DCs) are known to regulate immune responses. This study was performed to determine whether DCs are involved in the aetiology of sarcoidosis.

Methods: The numbers of peripheral blood DCs in 24 patients with sarcoidosis were analysed and biopsy specimens from four patients were stained immunohistochemically using monoclonal antibodies.

Results: The numbers of both myeloid and lymphoid DC subsets were significantly decreased in the blood and mature DCs were found in the granulomas of patients with sarcoidosis. A number of interferon- $\gamma$ (IFN$\gamma)$ producing $T$ cells were also detected in the sarcoid granuloma, as well as many interleukin (IL)-4 producing $T$ cells. Double staining of the biopsy specimen using anti-fascin and anti-CD3 antibodies showed an anatomical interaction between DCs and T cells.

Conclusions: These findings suggest that the blood DC subsets may migrate into the affected tissues, contributing to the formation of the granulomas in sarcoidosis. It is hypothesised that the migrating DCs may regulate the $T$ cell response in sarcoidosis, at least in the granulomatous lesions.
$\mathrm{S}$ arcoidosis is a systemic granulomatous disease, the aetiology of which remains unknown. In sarcoidosis the granulomas are organised structures composed of epithelioid cells, fibroblasts, and several immune cells such as $\mathrm{T}$ cells and histiocytes/macrophages. It has been shown that the granulomatous inflammation of sarcoidosis is characterised by the local $\mathrm{T}$ helper $\mathrm{l}$ (Thl) balance. ${ }^{1}$ However, it is unclear how this dominant Thl response is induced in the process of granuloma formation.

In the immune system, dendritic cells (DCs) function as specialised antigen-presenting cells (APCs) and play a central role in the initiation and regulation of $\mathrm{T}$ cell responses. ${ }^{23}$ Two major subsets of DC precursors have been identified in human peripheral blood ${ }^{4}$ : the CDllc+ subset belongs to the myeloid lineage, while the CDIlc- plasmacytoid subset (referred to as interferon (IFN) $-\alpha / \beta$ producing cells ${ }^{4-7}$ ) is of lymphoid lineage. Both DC subsets may migrate to tissues of various organs including lymphoid tissue, and they are therefore regarded as a circulating pool for the tissue DCs. ${ }^{8}$ 9

Recent research on DC biology has suggested that the DC subsets regulate different Th responses. The CDllc+ myeloid subset has a primary capacity to polarise naive CD4+ T cells towards IFN- $\gamma$ producing Thl cells depending on interleukin (IL)-12 production, while the CDIlc- subset preferentially induces IL-4 producing Th2 cells upon exposure to IL-3. ${ }^{10}{ }^{11}$ Evidence is emerging to suggest that these DCs play an important role in various disease conditions. Indeed, we have recently reported that, in primary Sjögren's syndrome, the CDllc+ DC subset is decreased due to selective trafficking from peripheral blood to the salivary glands, which suggests that DCs make an essential contribution in the pathophysiology of Sjögren's syndrome. ${ }^{12}$ In addition, recruitment of blood DCs to granulomatous lesions occurs in pulmonary tuberculosis, suggesting that DCs have a role in this condition. ${ }^{13}$ These findings have prompted us to examine whether DCs are also involved in sarcoidosis, another chronic inflammatory disease.

\section{METHODS \\ Patients}

Twenty four patients with sarcoidosis (eight men and 16 women) who presented to our hospital between May 2000 and February 2002 were enrolled in the study after providing informed consent. All patients were clinically and/or histologically diagnosed as having sarcoidosis. Their clinical stage was classified according to Wurm's radiological staging. ${ }^{14} 15$ Four patients were receiving treatment with corticosteroids at the time of the examination; the remaining 20 patients were not given corticosteroids during the study. The control group consisted of 24 age and sex matched volunteers. The characteristics of the patients and the control subjects are shown in table 1.

\section{Media}

The medium used in this study was RPMI 1640 supplemented with $2 \mathrm{mM}$ L-glutamine, $100 \mathrm{U} / \mathrm{ml}$ penicillin, $100 \mathrm{ng} / \mathrm{ml}$ streptomycin, and heat inactivated $10 \%$ fetal bovine serum (Irvine Scientific, Santa Ana, CA, USA).

\section{Enrichment and analyses of peripheral blood DCs}

Peripheral blood DCs were enriched according to the protocol described previously. ${ }^{12}{ }^{13}$ Briefly, the DC enriched population

\begin{tabular}{|c|c|c|}
\hline Characteristics & Patients ( $n=24$ ) & Controls $(n=24$ ) \\
\hline$M: F$ & $8: 16$ & $8: 16$ \\
\hline \multicolumn{3}{|c|}{ Median (range) age (years) } \\
\hline Male & $50(28-67)$ & $43(21-74)$ \\
\hline Female & $60(35-81)$ & $42(31-59)$ \\
\hline \multicolumn{3}{|l|}{ Stage } \\
\hline 0 & 6 & \\
\hline 1 & 10 & \\
\hline 2 & 5 & \\
\hline 3 & 3 & \\
\hline
\end{tabular}




\begin{tabular}{|c|c|c|c|c|c|c|c|}
\hline Patient/age/sex (biopsied tissue) & Stage & Corticosteroid & $\mathrm{WBC} / \mu \mathrm{l}$ & $\begin{array}{l}\text { PBMC } \\
\times 10^{5} / \mathrm{ml}\end{array}$ & Total DC/ml & $\begin{array}{l}\text { CDI lc+ } \\
\text { cells/ml }\end{array}$ & $\begin{array}{l}\text { CDIlc- } \\
\text { cells/ml }\end{array}$ \\
\hline $1 / 50 / \mathrm{M} /$ skin (leg) & 1 & + & 8600 & 38.8 & 1549 & 849 & 700 \\
\hline $2 / 60 / F /$ skin (arm) & 1 & - & 4300 & 21.8 & 1288 & 996 & 292 \\
\hline $3 / 55 / F / l y m p h$ node (cervical) & 1 & - & 5600 & 17.9 & 1460 & 948 & 512 \\
\hline 4/56/F/lymph node (cervical) & 2 & - & 4200 & 21.8 & 429 & 167 & 262 \\
\hline $5 / 60 / F$ & 2 & - & 5200 & 23.2 & 2312 & 1737 & 575 \\
\hline $6 / 41 / M$ & 3 & - & 4700 & 13.0 & 5135 & 3877 & 1258 \\
\hline $7 / 67 / M$ & 1 & - & 4000 & 20.4 & 5700 & 3757 & 1943 \\
\hline $8 / 53 / F$ & 0 & + & 9300 & 22.3 & 1052 & 345 & 707 \\
\hline $9 / 35 / F$ & 2 & + & 3900 & 22.5 & 701 & 411 & 290 \\
\hline $10 / 66 / M$ & 1 & + & 3400 & 66.7 & 1279 & 545 & 734 \\
\hline $11 / 64 / F$ & 0 & - & 5000 & 36.7 & 2256 & 1817 & 439 \\
\hline $12 / 28 / M$ & 0 & - & 5200 & 11.5 & 2701 & 1243 & 1458 \\
\hline $13 / 57 / F$ & 0 & - & 4400 & 17.0 & 5220 & 3696 & 1524 \\
\hline $14 / 65 / F$ & 1 & - & 3800 & 12.9 & 3491 & 1718 & 1773 \\
\hline $15 / 64 / F$ & 2 & - & 5300 & 28.7 & 5030 & 3869 & 1161 \\
\hline $16 / 61 / F$ & 1 & - & 6100 & 28.5 & 4460 & 3288 & 1172 \\
\hline $17 / 32 / M$ & 2 & - & 5200 & 17.4 & 6470 & 3358 & 3112 \\
\hline $18 / 59 / F$ & 3 & - & 4000 & 10.9 & 1041 & 826 & 215 \\
\hline $19 / 31 / M$ & 3 & - & 6600 & 4.6 & 706 & 75 & 631 \\
\hline $20 / 54 / F$ & 0 & - & 4800 & 8.0 & 4429 & 2436 & 1993 \\
\hline $21 / 54 / F$ & 1 & - & 5400 & 8.3 & 784 & 530 & 254 \\
\hline $22 / 81 / F$ & 1 & - & 6300 & 14.7 & 7360 & 5160 & 2200 \\
\hline $23 / 68 / F$ & 0 & - & 5200 & 49.9 & 2545 & 1057 & 1488 \\
\hline $24 / 54 / M$ & 1 & - & 5800 & 46.6 & 5432 & 2505 & 2927 \\
\hline
\end{tabular}

was obtained from peripheral blood mononuclear cells (PBMCs) by negative immunoselection using anti-CD3 (HIT3a; PharMingen, USA), anti-CD14 (M5E2; PharMingen), and anti-CD19 (B43; PharMingen) monoclonal antibodies (mAbs). The DC enriched population (CD3-/ CD14-/CD19- cells) was stained with phycoerythrin (PE) labelled anti-CD11c (Leu-5; Becton Dickinson, San Jose, CA, USA), a mixture of fluorescein isothiocyanate (FITC) labelled mAbs against lineage markers (lineage); CD3 (M2Ab; Exalpha, Boston, MA, USA), CDl4 (UCHMl; Ancell, Bayport, MN, USA), CD15 (80H5; Immunotech, Marseilles, France), CD16 (3G8; PharMingen), CD19 (HIB19; PharMingen), CD56 (NCAM16.2; Becton Dickinson, France), and phycoerythrincyanin 5.1 (PC5) labelled HLADR (IMMU357; Immunotech) and the cells were analysed by FACScan. The blood DC population was identified as the lineage-/HLA-DR+ fraction, which was further subdivided into a CDllc+ DC subset (CDIlc+/lineage-/HLA-DR+ cells) and a CDllc-DC subset (CDIlc-/lineage-/HLA-DR+ cells).

Absolute numbers (per ml) of peripheral blood DCs were calculated by multiplying the percentage of the lineage-/DR+ population in the DC enriched population by the count (per $\mathrm{ml}$ ) of the DC enriched population. The absolute number (per $\mathrm{ml}$ ) of each DC fraction was calculated by multiplying the percentage of each fraction within the lineage-/DR+ population by the total number of the lineage-/DR+ population.

\section{Immunohistochemical staining}

Biopsy specimens of lymph nodes from two patients with sarcoidosis (nos 6 and 18) and of skin (erythematous lesion) from two further patients (nos 1 and 7) were immediately fixed in $10 \%$ formalin solution, embedded in paraffin, and frozen. Histological examination was performed with haematoxylin and eosin staining and immunohistochemical staining using several mAbs. Anti-fascin mAb (55K-2; Dako), anti-HLA-DR mAb (LN-3; Nichirei, Tokyo, Japan), anti-IL-4 mAb (MAB304; RD, Minneapolis, MN, USA), antiCD4 mAb (1F6; Nichirei), and anti-CD8 mAb (C8/144B; Nichirei) were used for paraffin treated samples, and antiIFN- $\gamma$ mAb (45.15; Ancell), anti-IFN- $\alpha$ mAb (Genzyme,
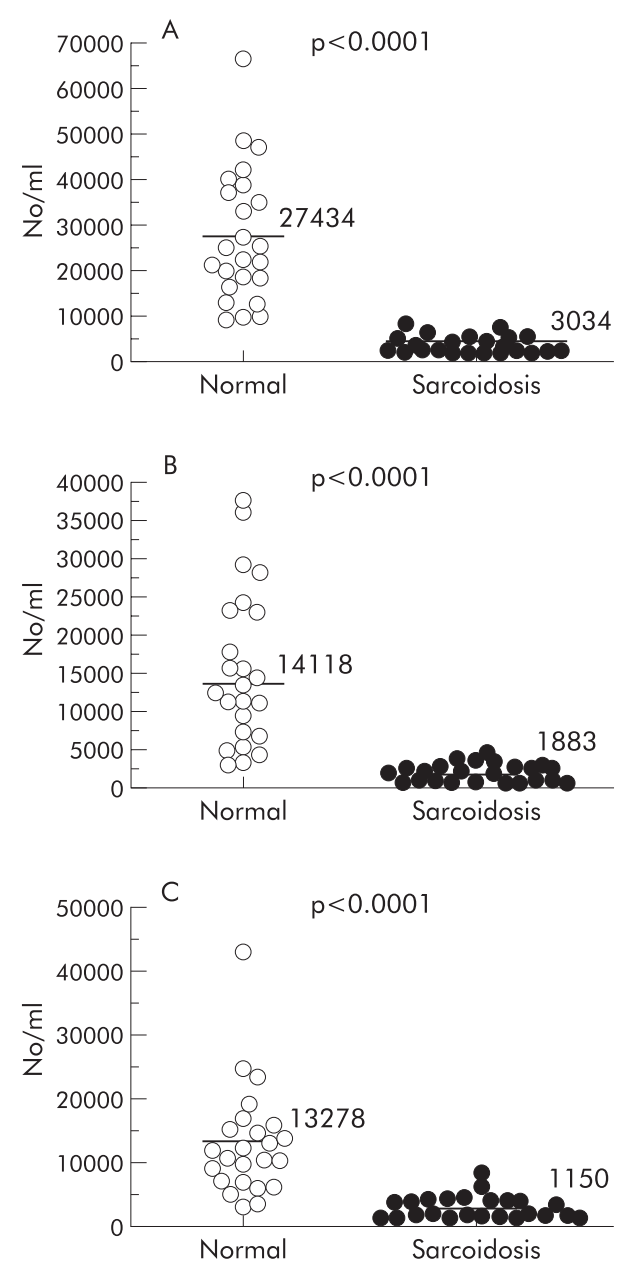

Figure 1 Mean number of (A) total blood dendritic cells (DCs), (B) CDIlc+ cells and (C) CDI lc- cells in patients with sarcoidosis. The numbers were significantly lower than in normal control subjects. 
Cambridge, MA, USA), anti-DC-LAMP mAb (104.G4; Immunotech), and anti-IL-4 mAb were used for frozen samples. The avidin-biotin-peroxidase complex method using a labelled streptavidin-biotin kit (Dako, Carpinteria, CA, USA) with haematoxylin and diaminobenzidine was used for immunohistochemical staining.

In addition, immunohistochemical double staining was performed on the tissue sections using the alkaline phosphatase technique. Anti-fascin mAb and anti-CD3 mAb (080102; Zymed, San Francisco, CA, USA), anti-fascin mAb and anti-HLA-DR mAb, anti- DC-LAMP $\mathrm{mAb}$ and anti-fascin $\mathrm{mAb}$, and anti-IL-4 mAb and anti-CD3 mAb were used as the primary and secondary antibodies, respectively.

\section{Statistical analysis}

The Mann-Whitney U test was used for statistical analysis with a StatView statistical program (Abacus Concepts, Berkley, CA). Differences were considered significant when $\mathrm{p}$ values were less than 0.05 .

\section{RESULTS}

\section{Numbers of blood DC subsets}

The white blood cell (WBC) count was within the normal range (3000-8000 cells/ $\mu \mathrm{l}$ ) in 22 of the 24 patients (table 2 ). Two patients (nos 1 and 8 ) had a slightly increased WBC count. There was no significant difference in WBC count between the patients and the normal controls (data not shown). However, the total number of peripheral blood DCs was significantly decreased in patients with sarcoidosis compared with normal healthy volunteers (sarcoidosis: mean 3034 cells/ml (range 429-7360); controls: mean 27434 cells/ $\mathrm{ml}$ (range 9775-66 580); $\mathrm{p}<0.001$, fig $1 \mathrm{~A}$ ). The numbers of CDllct and CDllc- DC subsets were also significantly decreased in patients with sarcoidosis (CDIlc+ DCs: sarcoidosis: mean 1883 cells/ml (range 75-5160); controls: mean 14118 cells $/ \mathrm{ml}$ (range 2426-36 366), p<0.001; CDllc- DCs: sarcoidosis: mean 1150 cells/ml (range 215-3112); controls: mean 13278 cells $/ \mathrm{ml}$ (range 3470-43 410); $<<0.001$, fig $1 \mathrm{~B}$, C). Although four of the 24 patients were being treated with corticosteroids at the time of the study, similar results were observed in the 20 patients who were not receiving corticosteroid treatment (total peripheral blood DCs: mean 3412 cells/ml; CDllc+ cells: mean 2148 cells/ml; CDllccells: mean 1259 cells/ml).

\section{Immunohistochemical staining of sarcoid granuloma}

Haematoxylin-eosin staining and immunohistochemical staining were performed on the biopsy samples of skin from two patients with sarcoidosis (nos 1 and 2) and of lymph node from two further patients (nos 3 and 4); similar results were obtained for all four specimens (figs 2, 3, and 4). Histological examination showed a pattern typical of sarcoid granuloma with an epithelioid core and a surrounding layer of infiltrated lymphocytes (fig 2A). A large number of CD4+ cells and a smaller but considerable number of CD8+ cells had infiltrated the lymphocyte layer (fig $2 \mathrm{~B}$ and $\mathrm{C}$ ). A number of fascin (mature DC specific marker) positive mononuclear cells were also found in this layer in sarcoid granulomas (fig 2D), as well as DC-LAMP (another DC specific marker) positive cells and HLA-DR positive cells (fig $2 \mathrm{E}$ and F). Double staining with anti-fascin mAb and anti-HLA-DR mAb showed that fascin positive cells were basically all HLA-DR positive (fig 3A and B). However, HLADR positive fascin negative cells were also detected. Furthermore, double staining showed that both fascin and DC-LAMP positive cells with prominent dendritic projections had infiltrated the lymphocyte layer (fig 3C). On the other
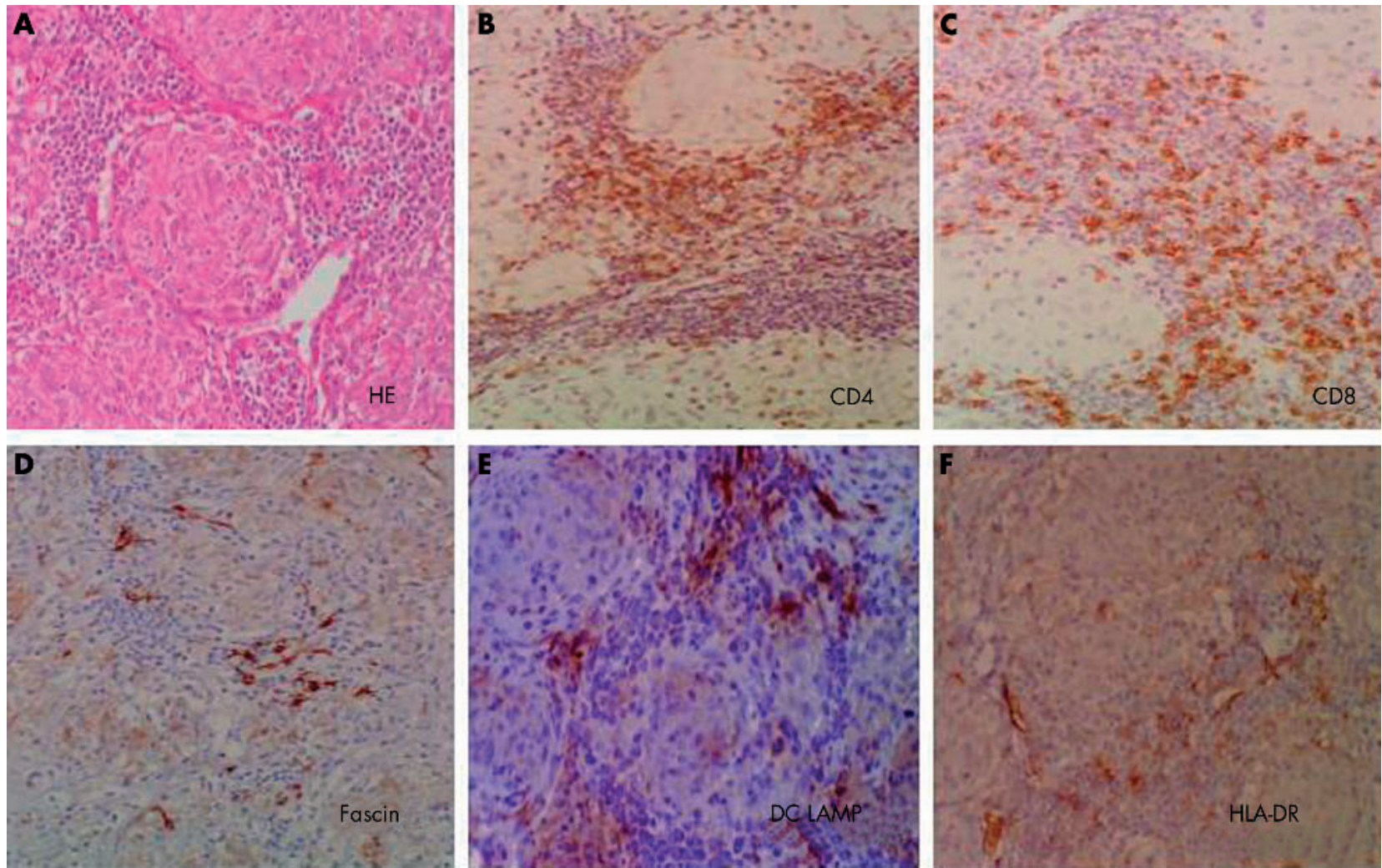

Figure 2 Immunohistochemical staining of lymph nodes of sarcoidosis. Representative data from one patient (no 3) are shown. (A) Haematoxylin and eosin; (B) anti-CD4- mAb; (C) CD8 - mAb; (D) fascin - mAb; (E) DC-LAMP- mAb; (F) HLA-DR- mAb. 
hand, double staining with anti-fascin mAb and anti-CD3 $\mathrm{mAb}$ showed that many CD3+ cells were in contact with fascin positive mononuclear cells in the lymphocyte layer (fig 3D and E), suggesting that DCs functionally interact with $\mathrm{T}$ cells in the granulomatous lesions of sarcoidosis.

We also found that many IFN- $\gamma$ producing cells had infiltrated the lymphocyte layer (fig 4A). A substantial number of IL-4 producing cells were also detected in the lymphocyte layer and also inside the epithelioid core of the granuloma (fig 4B). Double staining of IL-4 and CD3 revealed the existence of three types of cells in the granuloma: IL-4+ CD3+ cells, IL-4+ CD3 - cells, and IL-4- CD3+ cells (fig 4C and D). However, no IFN- $\alpha$ producing cells were seen in the biopsy samples. All of the histological findings described were observed in all four of the patients examined.

\section{DISCUSSION}

Accumulating evidence has shown that, under inflammatory conditions like infection, DCs infiltrate tissues in response to danger signals such as cytokines and chemokines. ${ }^{2}{ }^{3}$ We therefore hypothesised that blood DCs migrate to sarcoid granulomatous lesions where they accumulate, causing a decrease in blood DCs. In support of this hypothesis, we found that the number of total blood DCs was significantly decreased in patients with sarcoidosis. This decrease was the result of a significant decrease in both CDllc+ myeloid and CDIlc- plasmacytoid DC subsets. Histologically, a number of fascin+ HLA-DR+ cells and fascin+ DC-LAMP+ cells were found in the lymphocyte layer of the granuloma but not in the epithelioid core. Fascin is an actin bundling protein and is expressed in mature DCs, ${ }^{16}$ while DC-LAMP is a specific marker of lysosomes of mature DCs. ${ }^{17}$ HLA-DR, on the other hand, is not a specific but an essential molecule of DCs. Based on these findings, we concluded that a number of mature DCs infiltrated exclusively into the lymphocyte layer of the sarcoid granuloma. The decrease in immature blood DCs and the accumulation of mature DCs in the granuloma suggest that DCs experience a maturation process during or after their movement from the blood to the granuloma. Previous studies have suggested the presence of DCs in sarcoid granulomatous lesions because of the detection of S-100 positive cells. ${ }^{18}$ However, S-100 protein is not established as a highly specific marker of DCs. This study shows unequivocally that DCs infiltrate into sarcoid granulomas in humans. We have recently suggested that the recruitment of blood DC subsets to inflammatory lesions might occur in patients with tuberculosis. ${ }^{13}$ However, the blood DC subtype that predominantly decreases and the extent of the decrease seem to differ between tuberculosis and sarcoidosis. In tuberculosis the numbers of myeloid DCs, but not lymphoid DCs, are significantly decreased in the blood, whereas in sarcoidosis both DC subsets are significantly lower, suggesting a different level of involvement of DCs in the pathophysiology of the two diseases.

In a murine model of sarcoidosis CDllc+ DC precursors increased in the peripheral blood and DC precursors were recruited from the circulation into Propionibacterium acnes induced granulomas in the liver. ${ }^{19}$ This apparently differs from the findings in our study of decreased DC subsets in the blood of patients with sarcoidosis. This discrepancy may reflect different study conditions; the murine study looked at a relatively acute phase of bacteria induced granuloma formation while we examined a steady state chronic phase of the disease.
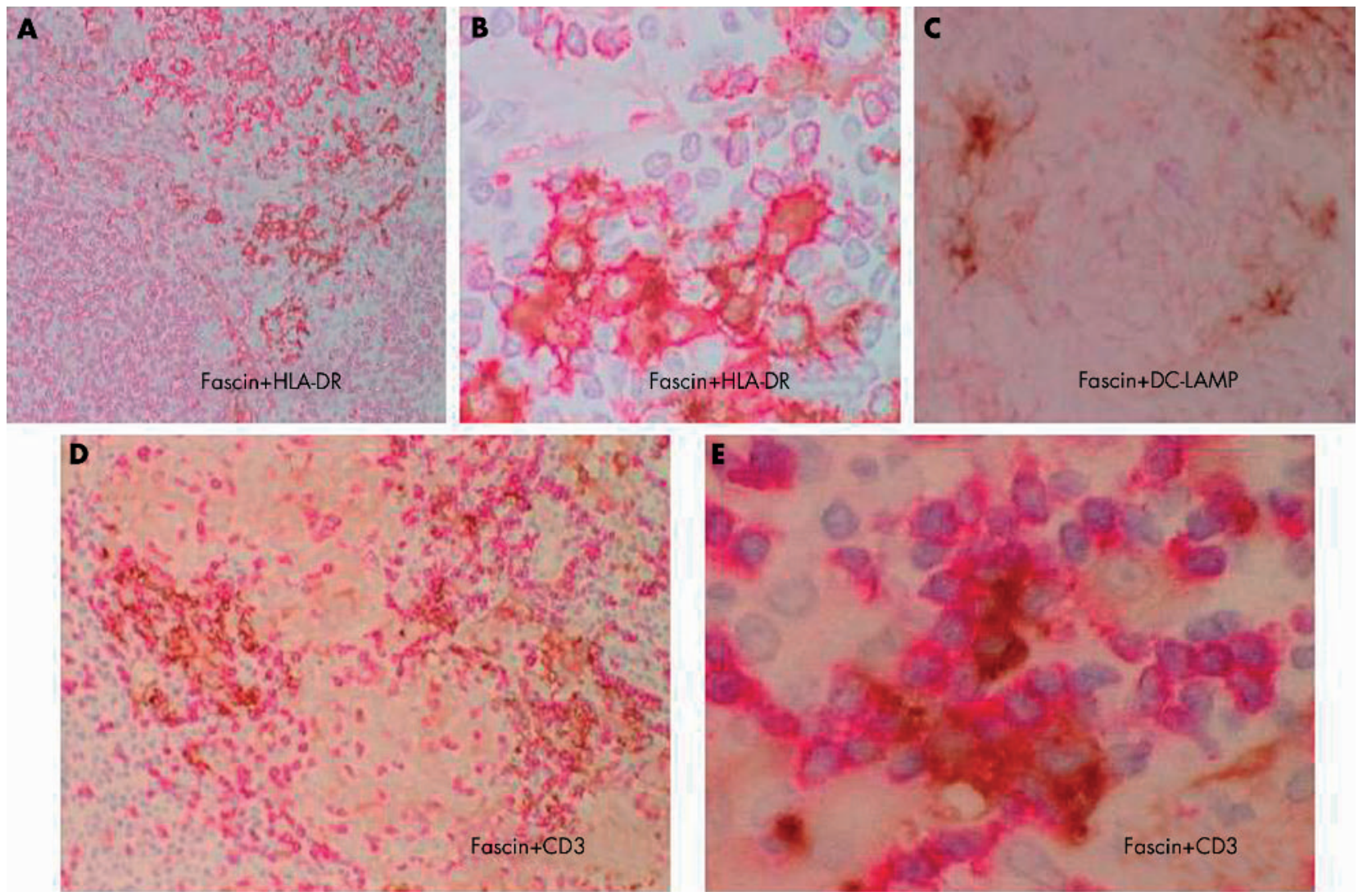

Figure 3 Immunohistochemical staining of lymph nodes of sarcoidosis. Representative data from two patients (no 2: A, B, C; no 3: D, E) are shown. $(A, B)$ Double staining with anti-HLA-DR $\mathrm{mAb}$ (red) and anti-fascin $\mathrm{mAb}$ (brown). Original magnification $\times 100$ (A) and $\times 1000$ (B). (C) Double staining with anti-DC-LAMP $m A b$ (red) and anti-fascin $m A b$ (brown). Original magnification $\times 500$. (D, E) Double staining with anti-CD3 $m A b$ (red) and antifascin $\mathrm{mAb}$ (brown). Original magnification $\times 200$ (D) and $\times 1000(\mathrm{E})$. 

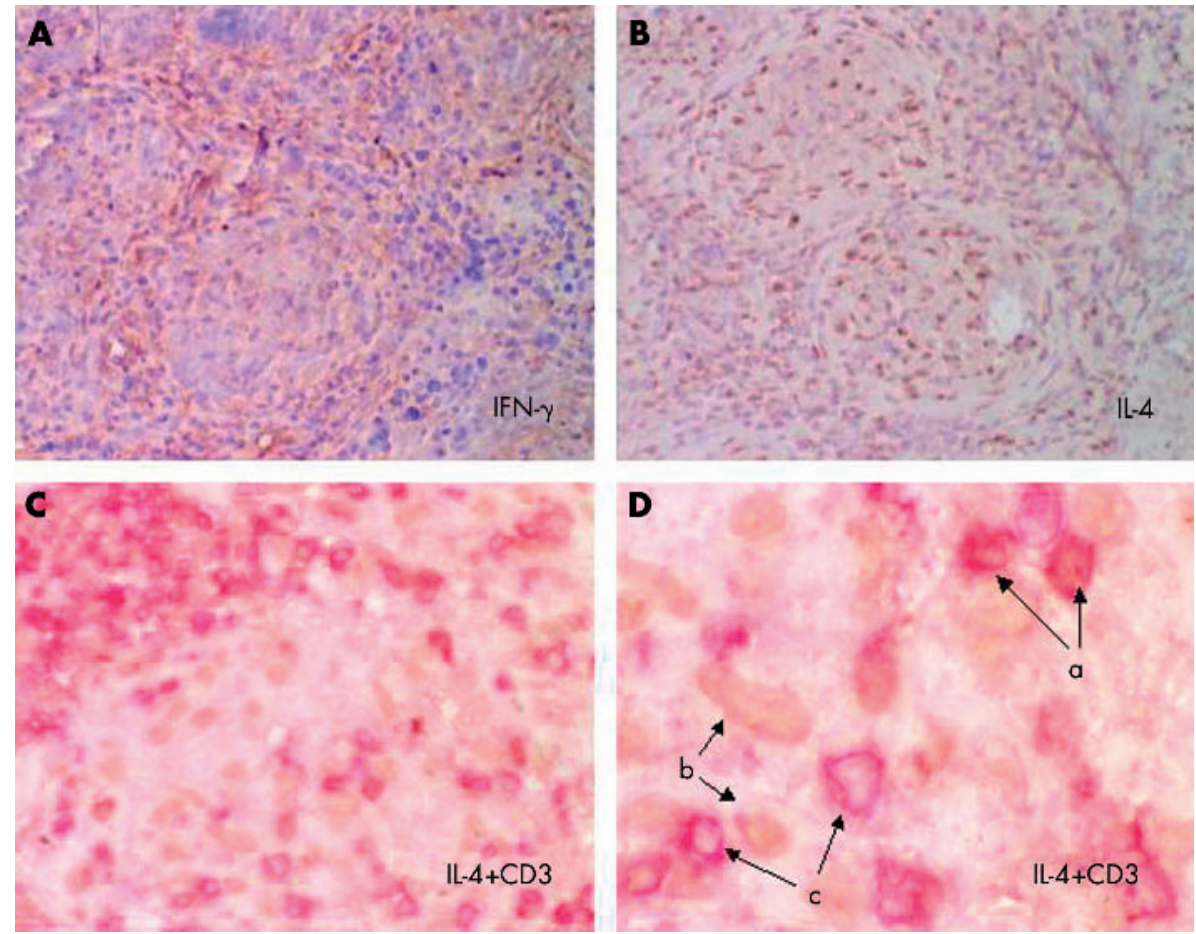

Figure 4 Immunohistochemical staining of lymph nodes and skin of patients with sarcoidosis. Representative data from two patients (no 3: A, B; no 1: $C, D$ ) are shown. (A, B) Staining with (A) anti-IFN $-\gamma-m A b$ and (B) IL-4 $-m A b$. Original magnification $\times 200$. (C, D) Double staining with anti-CD3 $\mathrm{mAb}$ (red) and anti-IL-4 mAb (brown). Original magnification $\times 500$ (C) and $\times 1000$ (D). (D) Staining of the epithelioid core of the granuloma showing three types of cells: (a) IL-4+CD3+ cells, (b) IL-4+CD3- cells, (c) IL-4- CD3+ cells.

We detected a number of IFN- $\gamma$ producing T cells mostly in the lymphocyte layer of the granuloma. These might be CD4+ or CD8+ because many CD4+ and CD8+ T cells were found to be infiltrating the lymphocyte layer. Previous studies have shown that IFN- $\gamma$ producing Thl cells accumulate predominantly in sarcoid granulomatous lesions, emphasising the importance of Th1 rather than Th2 in sarcoidosis. ${ }^{120-23}$ However, we also consistently found a significant number of IL-4 producing CD3+ T cells in the epithelioid core of the granuloma. This indicates the presence of Th2 cells or $\mathrm{T}$ cytotoxic type 2 (Tc2) cells, and suggests certain functional roles of these cells. One previous study suggested that Th2 cells were of relevance in pulmonary fibrosis in patients with sarcoidosis. ${ }^{24}$ However, all patients who were histologically examined for affected tissues in this study demonstrated the presence of IL-4 producing T cells in the granuloma despite the absence of pulmonary fibrosis. One possibility is that the IL-4 producing $\mathrm{T}$ cells reflect a feedback mechanism that attenuates an overload of Thl because IL- 4 is known to counteract IFN- $\gamma$ production of T cells. ${ }^{10}$ Interestingly, IL-4 producing CD3 - cells were also detected in the granuloma, especially in the epithelioid core. These might represent mast cells which are known to be present in granulomatous tissues. ${ }^{25}$

DCs play an essential role in the induction of antigenspecific $\mathrm{T}$ cell responses. ${ }^{2}{ }^{3}$ In the DC1/DC2 paradigm, DC1 (myeloid DCs) drive naive $\mathrm{T}$ cells towards Thl cells, while DC2 (lymphoid DCs) promote the differentiation of naive T cells into Th2 cells. ${ }^{10}$ It is therefore possible that the IFN- $\gamma$ producing $\mathrm{T}$ cells and the IL- 4 producing $\mathrm{T}$ cells found in the sarcoid granuloma are generated by the interaction with DC 1 and DC2, respectively. Indeed, double staining of fascin and CD3 showed an anatomical interaction between DCs and T cells in the lymphocyte layer of the sarcoid granuloma. Further studies of the expression profile of various cytokines and other molecules in these cells are needed to elucidate more precisely the nature of the interaction between these cell types.

In conclusion, we found a significant decrease in both myeloid and lymphoid DC subsets in the blood and an accumulation of DCs in the lymphocyte layer of granulomas in patients with sarcoidosis, implying a recruitment of blood DCs to the granuloma. We also found IFN- $\gamma$ producing T cells and IL-4 producing T cells in the sarcoid granuloma, which might be produced by an interaction with infiltrating DCs. These findings will help us to elucidate the pathophysiology of sarcoidosis and may open up new avenues of research into this enigmatic disease.

\section{Authors' affiliations}

M Ota, R Amakawa, K Uehira, T Ito, Y Yagi, A Oshiro, Y Date, H Oyaizu, T Shigeki, Y Ozaki, K Yamaguchi, S Fukuhara, First Department of Internal Medicine, Kansai Medical University, 10-15 Fumizono-cho, Moriguchi, Osaka 570-8506, Japan

Y Uemura, Surgical Pathology, Kansai Medical University, 10-15

Fumizono-cho, Moriguchi, Osaka 570-8506, Japan

S Yonezu, Department of Internal Medicine, Hyogo Prefectural Amagasaki Hospital, 1-1-1 Daimotsu-cho, Amagasaki, Hyogo 6600828, Japan

This work was supported by Research Fellowships of the Japan Society for the Promotion of Science for Young Scientists.

\section{REFERENCES}

1 Robinson BW, McLemore TL, Crystal RG, et al. Gamma interferon is spontaneously released by alveolar macrophages and lung T-lymphocytes in patients with pulmonary sarcoidosis. J Clin Invest 1985;75:1488-95.

2 Steinman RM. The dendritic cell system and its role in immunogenicity. Annu Rev Immunol 1991;9:271-96.

3 Banchereau J, Steinman RM. Dendritic cells and the control of immunity. Nature 1998;392:245-52.

4 O'Doherty U, Peng M, Gezelter S, et al. Human blood contents two subsets of dendritic cells, one immunologically mature and the other immature. Immunology 1994;82:487-93. 
5 Strobl H, Scheinecker C, Riedl E, et al. Identification of CD68+ lin- peripheral blood cells with dendritic precursor characteristics. J Immunol 1998; 161:740-8.

6 Ito T, Inaba M, Inaba K, et al. A CD la+/CD1 lc+ subset of human blood dendritic cells is a direct precursor of Langerhans cells. J Immunol 1999;163:1409-19.

7 Siegal FP, Kadowaki N, Shodell M, et al. The nature of the principal type 1 interferon-producing cells in human blood. Science 1999;284:1835-7.

8 Steven DR, Giuseppe P, Luciano A, et al. The control of T cell responses by dendritic cell subsets. Curr Opin Immunol 2000;12:114-21.

9 Hart DN. Dendritic cells: unique leukocyte populations which control the primary immune response. Blood 1997;90:3245-87.

10 Rissoan MC, Soumelis V, Kadowaki N, et al. Reciprocal control of T helper cell and dendritic cell differentiation. Science 1999;283:1183-6.

11 Grouard G, Rissoan MC, Filgueira L, et al. The enigmatic plasmacytoid T cells develop into dendritic cells with interleukin(IL)-3 and CD40-ligand. J Exp Med 1997; 185:1101-11

12 Ozaki Y, Amakawa R, Ito T, et al. Alteration of peripheral blood dendritic cells in patients with primary Sjögren's syndrome. Arthritis Rheum 2001:44:419-31.

13 Uehira K, Amakawa R, Ito T, et al. Dendritic cells are decreased in blood and accumulated in granuloma in tuberculosis. Clin Immunol 2002;105:296-303.

14 Wurm K, Reindell H, Heilmyer L. Der Lun genboeck in Rontgebild. Stuttgart: George Thieme, 1958.

15 ATS/ERS/WASOG. Statement of sarcoidosis. Sarcoid Vasc Diffuse Lung Dis 1999;16:147-73.

16 Pinkus GS, Pinkus JL, Langhoff E, et al. Fascin, a sensitive new marker for Reed-Sternberg cells of Hodgkin's disease. Evidence for a dendritic or B cell derivation? Am J Pathol 1997;150:543-62.
17 Arkema JM Schadee-Eestermans IL, Broekhuis-Fluitsma DM et al. Double labeling of major histocompatibility complex molecules and lysosomal protein LAMP-1 on human dendritic cells. Histochem J 1994;26:95-9.

18 Abe Y, Tsuda T, Okajima T, et al. In vitro angiotensin-converting enzyme and interleukin-1 production by epithelioid cells isolated from induced rabbit lung granuloma. Exp Lung Res 1990;16:489-505.

19 Yoneyama H, Matsuno K, Zhang Y, et al. Regulation by chemokines of circulating dendritic cells precursors, and the formation of portal tractassociated lymphoid tissue, in a granulomatous liver disease. J Exp Med 2001;193:35-49.

20 Kita S, Tsuda T, Sugisaki K, et al. Characterization of distribution of T lymphocytes subsets and activated T lymphocytes infiltrating into sarcoid lesions. Intern Med 1995;34:847-55.

21 Fukami T, Miyazaki E, Matsumoto T, et al. Elevated expression of interleukin18 in the granulomatous lesions of muscular sarcoidosis. Clin Immunol 2001;101:12-20.

22 Moller DR, Forman JD, Liu MC, et al. Enhanced expression of IL-12 associated with Th1 cytokine profiles in active pulmonary sarcoidosis. J Immunol 1996; 145:4952-60.

23 Wahlstrom J, Katchar K, Wigzell H, et al. Analysis of intracellular cytokines in CD4+ andCD8+ lung and blood T cells in sarcoidosis. Am J Respir Crit Care Med 2001;163:115-21.

24 Zissel G, Homolka J, Schlaak J, et al. Anti-inflammatory cytokine release by alveolar macrophages in pulmonary sarcoidosis. Am J Respir Crit Care Med 1996;145:713-9.

25 Celasun B, Crow J, Scheuer PJ. Mast cell in granulomatous liver disease. Pathol Res Pract 1992;188:97-100.

\section{LUNG ALERT}

A rapid diagnostic test for ventilator associated pneumonia?

$\Delta$ Gibot S, Cravoisy A, Levy B, et al. Soluble triggering receptor expressed on myeloid cells and the diagnosis of pneumonia. N Engl J Med 2004;350:451-8

$\mathrm{T}$

he diagnosis of ventilator associated pneumonia (VAP) is both contentious and frustrating for the intensivist. This study evaluates the effectiveness of using soluble

triggering receptor expressed on myeloid cells (sTREM)-1, a member of the immunoglobulin superfamily expressed in response to bacterial or fungal infections, as a tool for the rapid diagnosis of VAP. A total of 148 patients requiring mechanical ventilation and with a clinical suspicion of pneumonia were prospectively enrolled in the study. Mini bronchoalveolar lavage was performed and the collected sample used for quantitative bacterial culture and assay of STREM-1 and the inflammatory cytokines tumour necrosis factor (TNF)- $\alpha$ and interleukin (IL)- $1 \beta$. VAP was diagnosed on the basis of new persistent infiltrates on chest radiography, significant bacterial growth on culture $\left(\geqslant 10^{3} \mathrm{CFU} / \mathrm{ml}\right.$ of lavage fluid), and either purulent tracheal secretions, pyrexia, leucocytosis, or leucopenia. The STREM- 1 assay reliably diagnosed pneumonia with a sensitivity of $98 \%$ and specificity of $90 \%$. Using multiple logistic regression analysis among the predictors of pneumonia (clinical pulmonary infection score, sTREM-1, TNF- $\alpha$ and IL- $1 \beta$ ), sTREM-1 emerged as the strongest indicator (odds ratio 41.5).

The authors conclude that STREM- 1 assay may be a useful tool in both the rapid diagnosis of VAP and the reliable differentiation from non-infectious causes of fever and radiographic pulmonary infiltrates in ventilated patients.

S Zachariah

Specialist Registrar, Lok Nayak Hospital, Delhi, India sanjayzak@hotmail.com 